Al-Nimma: THD reduction using series transformer connection in a STATCOM within......

\title{
THD Reduction Using Series Transformer Connection In A STATCOM Within Mosul Ring System
}

\author{
Dhaiya A. Al-Nimma \\ Assist. Prof
}

\section{Majed S. Al-Hafid}

Assist. Prof

Elect. Eng / University of Mosul

\section{Yasser A. Mahmood}

Assist. Lecturer

\section{Abstract}

The static synchronous compensator (STATCOM) is one of the components of Flexible AC Transmission System (FACT). STATCOM is used to compensate the reactive power with fast response. It consist of power electronic devices. The main drawback of STATCOM is harmonics injection to the system. Different techniques can be used to reduce harmonic injection, such as the use of 12-pulse STATCOM with Pulse Width Modulation (PWM) to control the operation of power electronic devices.

In this work the series connection of transformers is studied and compared with parallel connection. The study is applied to the suggested STATCOM in the ring system around Mosul city. Matlab / Simulink is used to analyze the two systems. The results are given and discussed in the paper. Also it is found that the Total Harmonic Distortion (THD) can be further reduced by using series connection of transformers secondary rather than shunt connection.

Keywords :STATCOM, Harmonic reduction, Transformer connection in STATCOM, Mosul distribution ring.

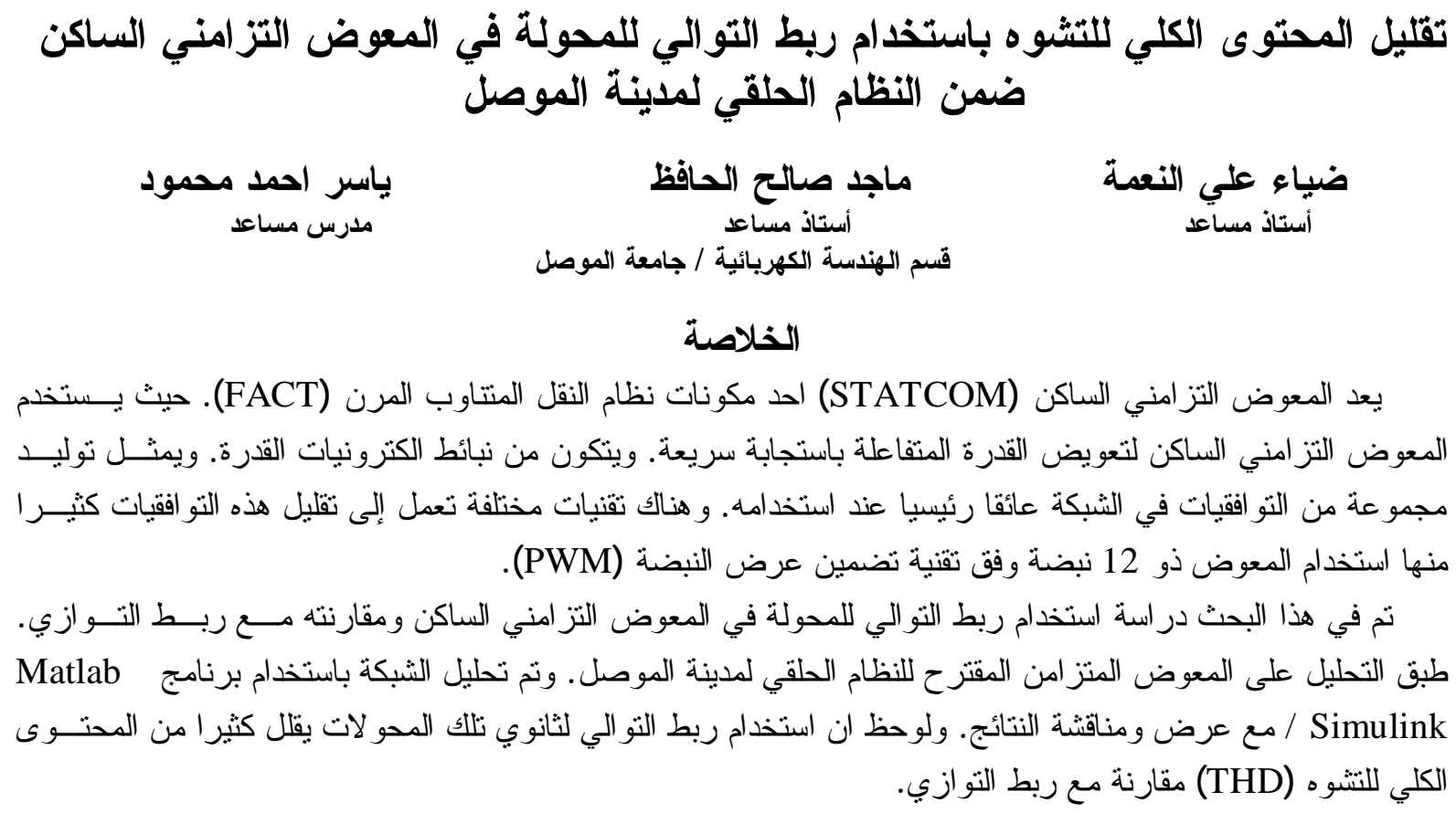




\section{$\begin{array}{llll}\text { Al-Rafidain Engineering } & \text { Vol.17 } & \text { No.5 } & \text { October } 2009\end{array}$}

\section{1: Introduction}

The Iraqi North Region National Grid (INRNG) consists of $400 \mathrm{KV}$ and $132 \mathrm{KV}$ buses. The load of Mosul city represents an important part of the INRING load. This load is supplied by a ring consists of seven $132 \mathrm{KV}$ buses as shown in Figure 1. The lines connecting the buses are mainly double circuits. There are three single circuit lines $(35 / 36,36 / 37 \& 35 / 37)$. This part of the INRNG suffers from problems such as loading on these three lines can exceed the acceptable loading percent during peak load periods. This causes outage due to over load.

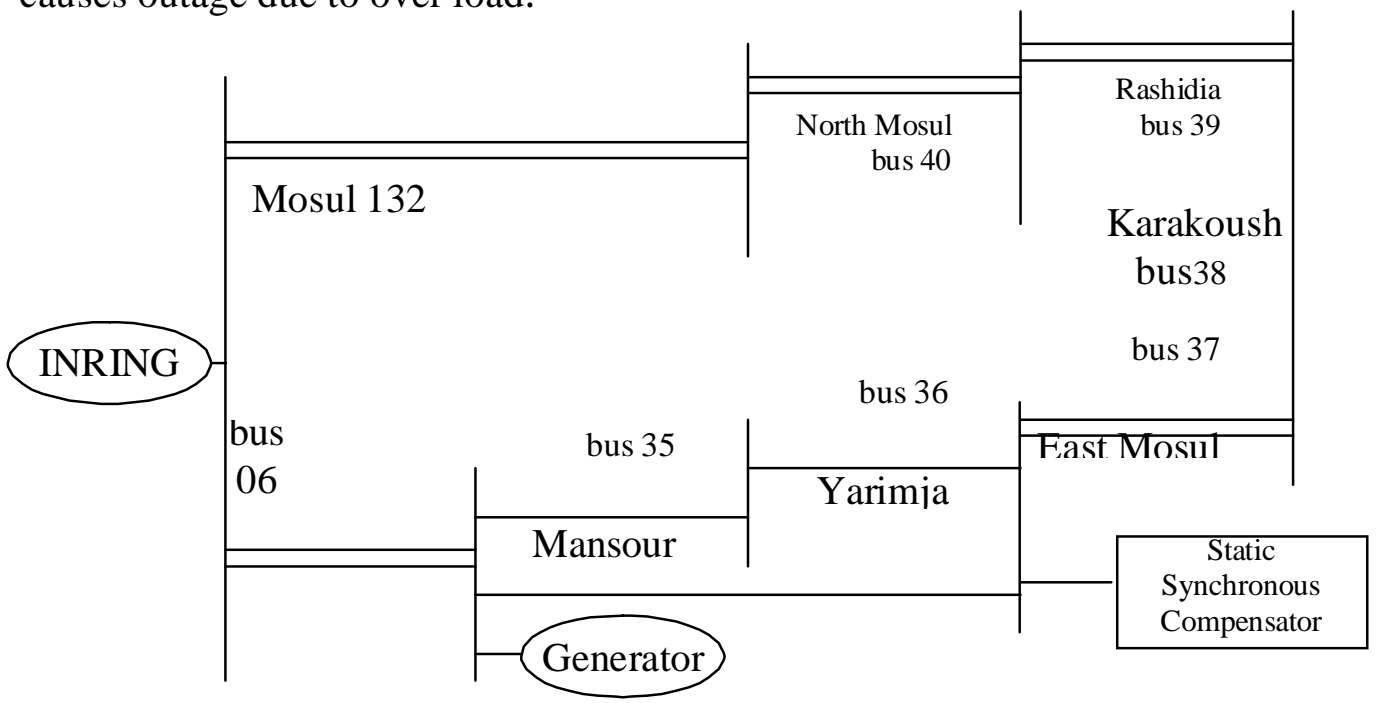

Figure 1: Mosul city 132kV ring system

The lines over load can be reduced by supplying reactive power locally. STATCOM has many advantage like High power rating, accurate and continuous control of reactive power and fast response to improve transient stability. So a STATCOM have been suggested in the Mosul Ring[1]. In this paper, INRING is analyzed using a load flow program. The buses $36,37, \& 38$ were suffering from low voltages. So these three buses were the possible location of the STATCOM. The proposed STATCOM [1] was added in one of the three week buses each time. The same load flow program was then used to analyze INRING. The added reactive power, voltage profile of the Mosul ring busses, total losses for the three cases were compared East Mosul ring bus (bus 37) was preferred for the connection of the STATCOM[1].

STATCOM injects harmonics to the system. These added harmonics can be reduced by the proper selection of its components such as leakage reactance, switching frequency, number of pulses. Also the injected harmonics can be reduced by using (PWM) techniques. The selection of appropriate component of the suggested STATCOM have been done in a previous work[2].

The 12- pulse STATCOM with PWM is recommended, due to its low THD[1,2]. The HV windings of the two 6- pulse STATCOM transformers can be connected either in parallel [1,2] or in series [3,4]. The two connections are shown in figures $2 \& 3$ respectively. In both cases PWM technique is used to five the switching devices of the STATCOM.

The analysis of two connection of the STATCOM transformers (series \& parallel) is done for the suggested model in Mosul ring. The Matlab/Simulink software V6.5 is used in this analysis[4]. THD and wave forms of current and voltages for the two cases are presented and discussed in the following articles. 
Al-Nimma: THD reduction using series transformer connection in a STATCOM within......



LV

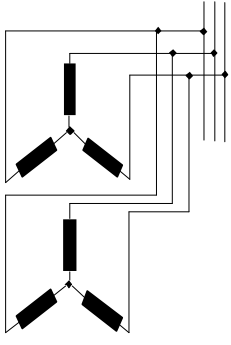

$\mathrm{HV}$

Figure 2: parallel connection

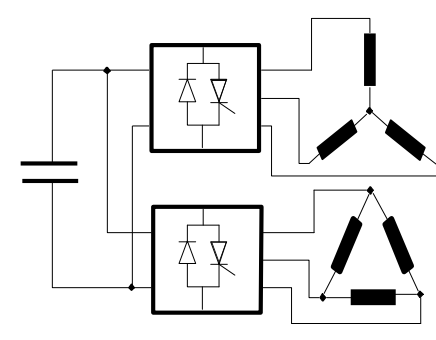

$\mathrm{LV}$

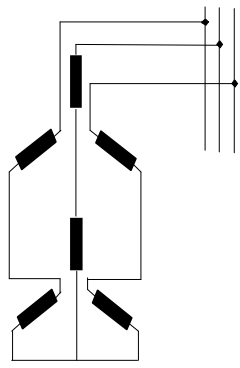

$\mathrm{HV}$

Figure 3: series connection

\section{2: System of Analysis:}

\section{2-1: THD Calculations:}

THD is used to define the effect of harmonics on the power system voltage. It is used in low-voltage, medium-voltage and high-voltage systems. It is expressed as a percent of the fundamental and is defined as:-

$$
\begin{gathered}
\text { THD }=\sqrt{\frac{\text { sum of all squares of amplitude of all harmonic voltages }}{\text { square of the amplitude of the fundamental voltage }}} * 100 \% \\
T H D=\frac{\sqrt{\sum_{h=2}^{\infty} V_{h}^{2}}}{V_{1}} * 100 \%
\end{gathered}
$$

The limits lists in table 1 should be used as system design values for the "worst case" for normal operation (conditions lasting longer than one hour). For shorter period, during start-up or unusual conditions, the limits may be exceeded by 50\% [5].

Table 1: Voltage Distortion Limits

\begin{tabular}{|l|c|c|}
\hline Bus Voltage $(\mathbf{k V})$ & Individual Voltage Distortion & Total Voltage Distortion THD(\%) \\
\hline 69 and below & 3.0 & 5.0 \\
\hline 69 through 161 & 1.5 & 2.5 \\
\hline 161 and above & 1.0 & 1.5 \\
\hline
\end{tabular}

\section{2-2: System Data}

INRNG load is $1122 \mathrm{MW}$ and $543.8 \mathrm{Mvar}$. Mosul ring load is $316 \mathrm{MW}, 167 \mathrm{Mvar}$. Mosul ring busses and lines data are given in appendix A. the loading conditions are changed continuously, so to operate the STATCOM optimally, this change must be taken in to consideration. The load range 70-150\% (of the reference load) is considered. The values of the reactive power required to be supplied by the STATCOM for this load range was obtained from a previous work[1].

\section{2-3:Analysis Model}

Mosul ring with STATCOM situated at bus 37 is analyzed, using Matlab/Simulink software V6.5. Fig 4 shows the simulink model of the STATCOM, where the main idea of this research, it is the two transformers are connected, is clearly shown. 


\section{$\begin{array}{llll}\text { Al-Rafidain Engineering } & \text { Vol.17 } & \text { No.5 } & \text { October } 2009\end{array}$}

The load range with suitable step change is used in the analysis model. The delay angle value is obtained according to active $\&$ reactive power required. Then it used in the model to obtained the THD. The Graphic User Interface (GUI) is used to get the harmonic content of voltage and current waveforms in each case. It also give THD of the analyzed waves. THD for voltages and currents (for the load range steps) are found at different buses. They are Bus 37, where the STATCOM is connected, Bus 39, a typical load bus, and bus 6 a generator bus.

Transformer ratio should be carefully chosen to match grid system in both cases. In both cases (parallel and series) the first transformer is star-star connected. While the second transformer is delta-star connected. For the parallel connection the star-star transformer is $(13.8 \mathrm{kV} / 132 \mathrm{kV})$ as line to line voltages. While the delta-star transformer is of $(13.8 \mathrm{kV} / 132 \mathrm{kV})$ as line to line voltages. As regard the series connection, the star-star transformer is of $\left(\frac{13.8}{\sqrt{3}} \mathrm{kV} / \frac{66}{\sqrt{3}} \mathrm{kV}\right)$ as phase voltages. While the delta-star transformer is of $\left(13.8 \mathrm{kV} / \frac{66}{\sqrt{3}} \mathrm{kV}\right)$ as phase voltages. The sum of the two voltages of the series connection secondaries is therefore $\frac{132}{\sqrt{3}} \mathrm{kV}$ as a phase voltage and $132 \mathrm{kV}$ as a line voltage. This configuration makes the two six pulse bridge share the reactive power in both the parallel $\&$ the series connections.



Figure 4: Simulink Model 
Al-Nimma: THD reduction using series transformer connection in a STATCOM within...... 3: Results and Discussion

The THD of the voltages and the currents at buses 37, 39 and 6 are found. Figure 5 shows the THD of the voltages at the two buses $37 \& 39$, for the two cases (series and parallel secondary) at $100 \%$ loading. It is clear that the THD at bus 37 is higher, since the STATCOM is connected at this bus. It is also clear from this figure that the THD of the series connection is less than that for parallel connection by $2 \%$. Figure 6 shows the THD of the currents at four locations: the STATCOM current, bus $37 \& 39$ load currents and bus 6 generator current. Clearly The THD of the STATCOM (10\%) current is the highest. Again the THD in the case of series connection is lower than in the case of parallel connection.

Results for the THD of voltages and currents for different loading conditions (70\% $-150 \%$ ) are also obtained. Since THD at bus 37 is the highest the results at this bus is chosen. Figure 7 shows the THD of the voltage waves at bus 37, for the two cases (series and parallel secondary). The THD for the case of parallel connection is less than 5\% which is within standard limits and the THD of the series connection (less than 3\%) is even lower. Figure 8 shows the THD at the same bus 37 but for the current waves. The same conclusion applies for this case. It is clear from both figures $7 \& 8$ that the THD for all cases remains almost constant with loading conditions.



Figure 5: Voltage THD in buses $37 \& 39$ at $100 \%$ loaded

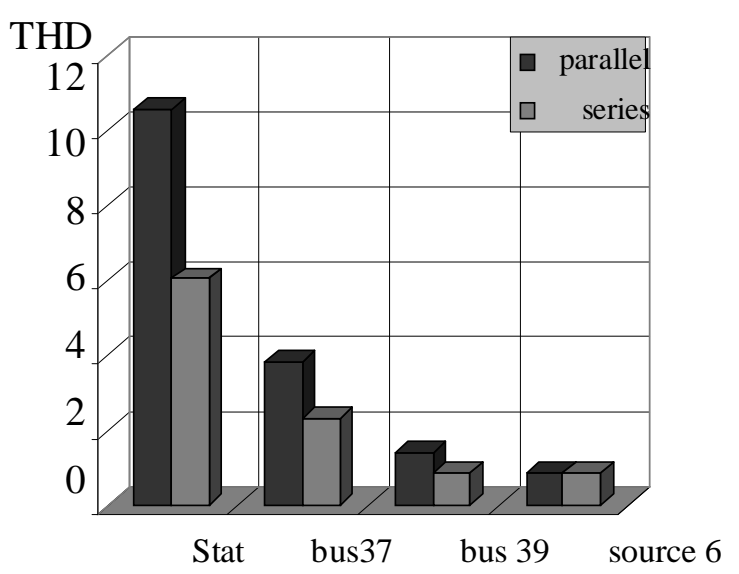

Figure 6: Current THD in Buses 6, 37, 39 and STATCOM, at $100 \%$ loaded

Figure $9 \& 11$ show the voltage waveform at bus 37 (bus of STATCOM connection) \& the current waveform at STATCOM, in series connection of transformers, respectively. The current waveform contain more harmonic components than voltage. This fact is clear from the figures $5 \& 6$.

Figures $10 \& 12$ show the spectrum of the voltage waveform at bus $37 \&$ the spectrum of the current waveform of the STATCOM, respectively for the series connection. It is clear from these two figures that the dominant harmonic components of both the voltage and the current waveforms are $19^{\text {th }}, 23^{\text {rd }}, 41^{\text {st }}, 43^{\text {rd }} \ldots$. The corresponding waveforms and spectrum for parallel connection are given in reference [2] and appendix B for comparison. It is clear that the harmonic content of both voltage \& current are less in series connection. The individual harmonics example the $5^{\text {th }}, 19^{\text {th }}, 23^{\text {rd }}, 41^{\text {st }}, 43^{\text {rd }}$, each of them has been reduced. The $3^{\text {rd }}, 17^{\text {th }}$, $21^{\text {st }}, 25^{\text {th }}$. Harmonics for the voltage and the $21^{\text {st }}, 39^{\text {th }}, 45^{\text {th }}$ for the current are deleted. 


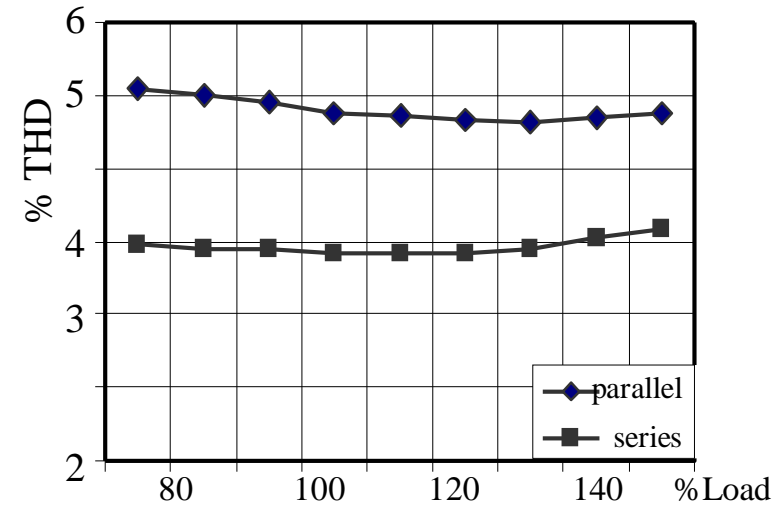

Figure7: THD of the voltage at bus 37 VS $\%$ loading

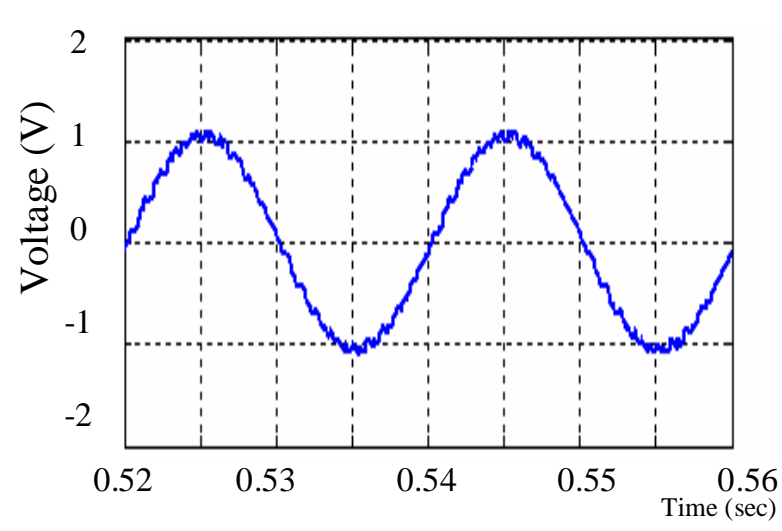

Figure 9: The voltage waveform at bus 37

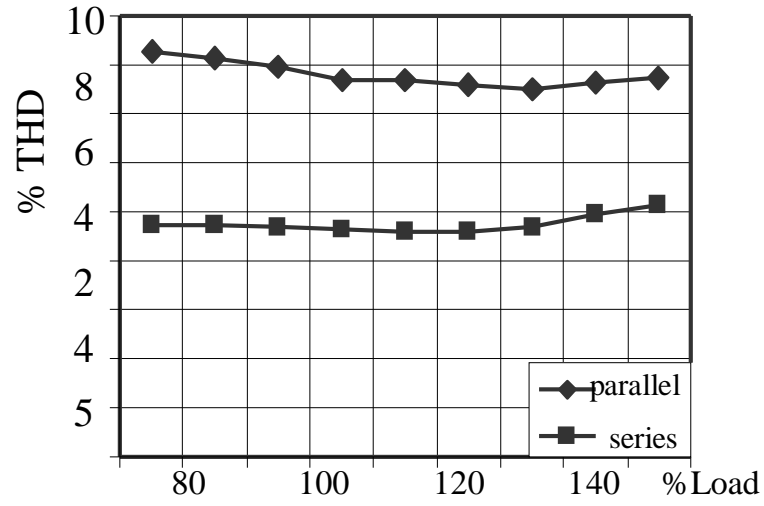

Figure 8: THD of the current at bus 37 VS $\%$ loading

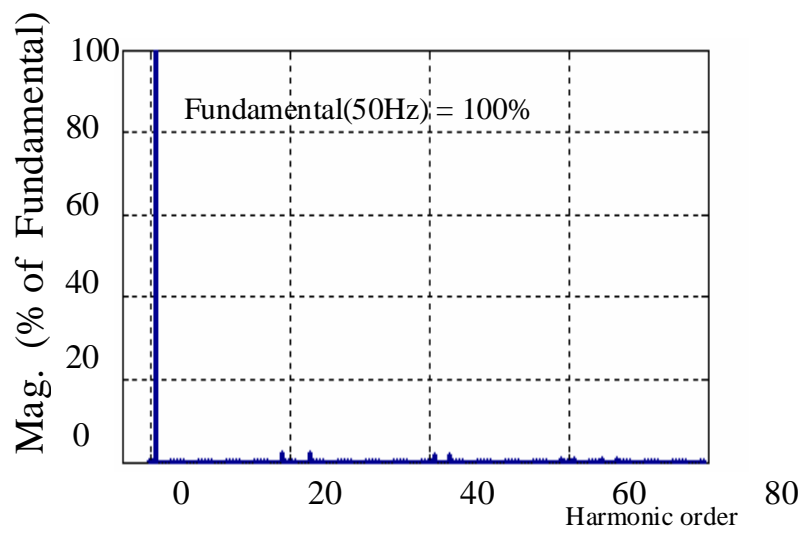

Figure 10: The spectrum analysis of a voltage waveform at bus 37

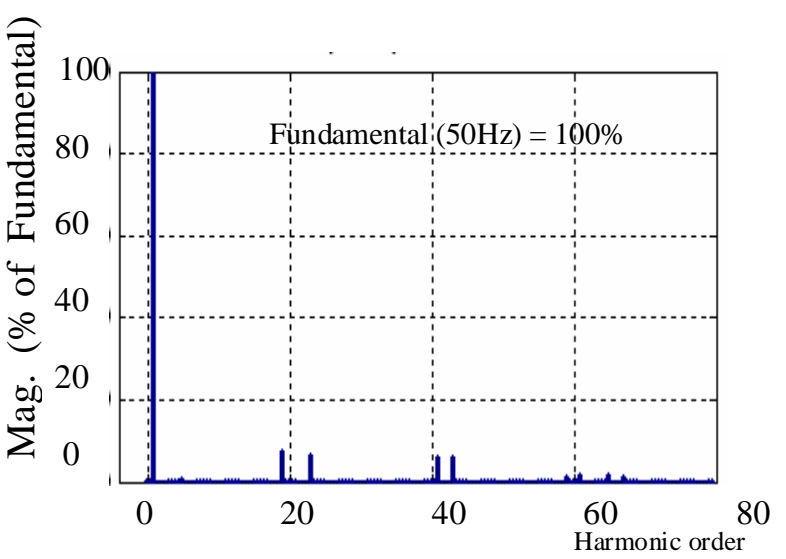

Figure 12: The spectrum analysis of a current waveform at STATCOM 
Al-Nimma: THD reduction using series transformer connection in a STATCOM within...... 4: Conclusions

The suggestion of using static synchronous compensator in the $132 \mathrm{kV}$ ring system of Mosul city is a promising solution for the problems encountered in it. By implementing, PWM technique in a 12 pulse STATCOM with conventional transformer connections a total harmonic distortion of less than 5\% may be obtained which is within standard limits. In this work it is found that this amount of distortion can be further reduced (by $3 \%$ ) by using transformers with series connection rather than the conventional parallel connection. Furthermore some individual harmonics like $21^{\text {st }}$ have been deleted.

\section{5: References}

1. Dr. Dhiya A. Al-Nimma \& Majed S. Al-Hafid "An Intelligent technique for optimizing the operation of a static synchronous compensator in northern Iraqi network" Al-Rafidain Engineering Journal Vol. 13, No.3, 2005, PP 9-20.

2. E. Uzunovic, C. A. Canizares and J. Reeve "Fundamental frequency model of static synchronous compensator" North American Power symposium (NAPS), Laramie, Wyoming, Oct, 1997, pp 49 / 54.

3. Majed S. Al-Hafid \& Dr. Dhiya A. Al-Nimma " Application of ANN for reducing THD by a combined STATCOM and capacitor bank combination system" The 6th JIEEEC 14 - 16 March 2006, Amman, Jordan, PP 301-307.

4. The Math Work Inc, Simulink use with Matlab 2002, MA, USA.

5. W. Shepherd "IEEE Recommended Practices and Requirements for Harmonic Control in Electrical Power Systems" IEEE std, 519-1992 April, 12, 1993.

\section{Appendix A}

Table A-1: Mosul City Ring System Loads.

\begin{tabular}{|l|l|l|l|}
\hline No & Name & Load (MW) & Load (MVAR) \\
\hline $\mathbf{6}$ & Mosul 132 & 0 & 0 \\
\hline $\mathbf{3 5}$ & Mansour & 23 & 5 \\
\hline $\mathbf{3 6}$ & Yarimja & 53 & 35 \\
\hline $\mathbf{3 7}$ & East Mosul & 64 & 46 \\
\hline $\mathbf{3 8}$ & Karakous & 94 & 21 \\
\hline $\mathbf{3 9}$ & Rashidia & 70 & 23 \\
\hline $\mathbf{4 0}$ & North Mosul & 57 & 37 \\
\hline
\end{tabular}

Table A-2: Mosul City Ring System Parameters.

\begin{tabular}{|l|l|l|l|l|l|}
\hline Sending Ends & Receiving Ends & R (p.u.) & X (p.u.) & Y (p.u.) & No. of Lines \\
\hline 6 & 35 & 0.0066 & 0.0140 & 0.00250 & 2 \\
\hline 6 & 40 & 0.0044 & 0.0094 & 0.00160 & 2 \\
\hline 35 & 36 & 0.0150 & 0.0687 & 0.02479 & 1 \\
\hline 35 & 37 & 0.0185 & 0.0850 & 0.03128 & 1 \\
\hline 36 & 37 & 0.00554 & 0.00251 & 0.00870 & 1 \\
\hline 37 & 38 & 0.0125 & 0.0574 & 0.02114 & 2 \\
\hline 33 & 39 & 0.2020 & 0.0420 & 0.00716 & 2 \\
\hline 39 & 40 & 0.01003 & 0.0212 & 0.00379 & 2 \\
\hline
\end{tabular}




\section{Appendix B}

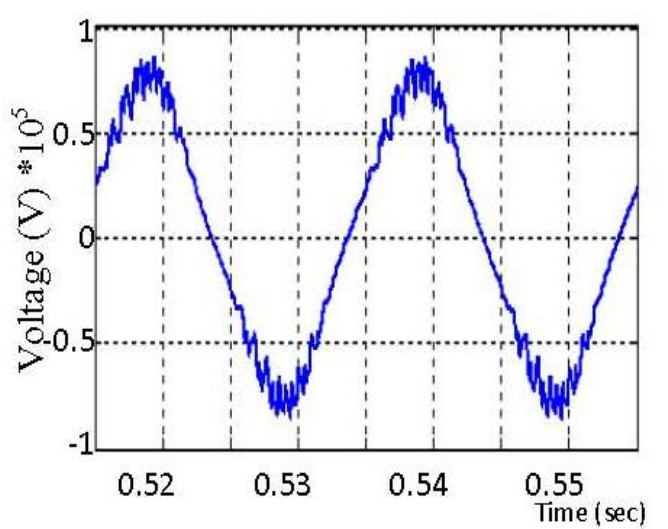

Figure B1: The voltage waveform at bus 37 for parallel connection

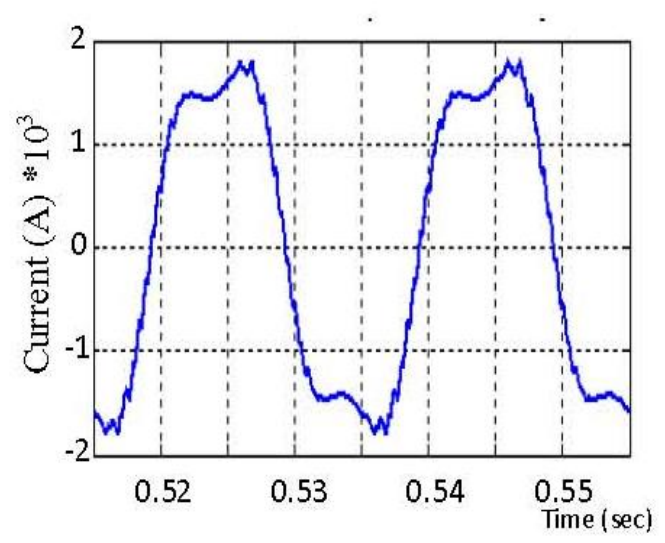

Figure B3: The current waveform at STATCOM for series conn.

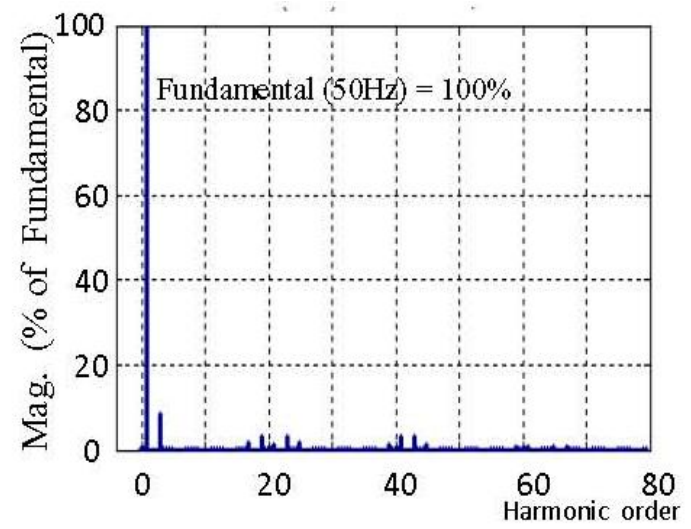

Figure B2: The spectrum analysis of a voltage waveform at bus 37 for parallel conn.

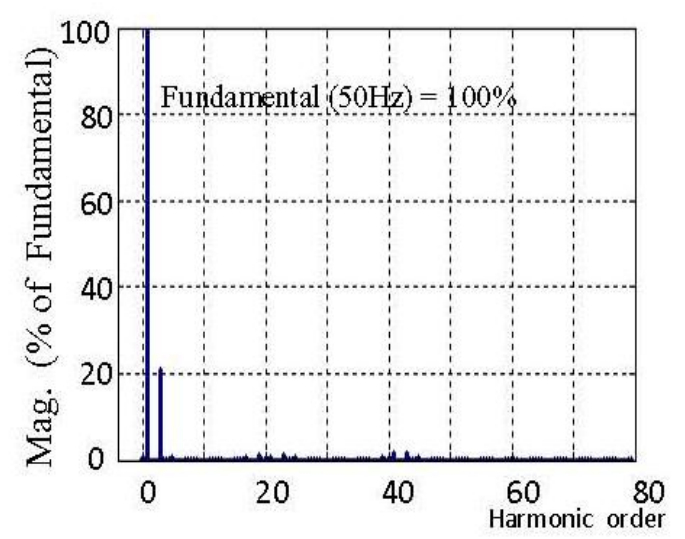

Figure B4: The spectrum analysis of a current waveform at STATCOM for series conn. 